\title{
Paravaulting as a possibility of integration in the sport of people with disabilities
}

\author{
JANA SKLENAŘÍKOVÁ \\ Department of Physical Education and Sport, Faculty of Education, Catholic University, Slovakia
}

\begin{abstract}
Sklenaříková, J. (2014). Paravaulting as a possibility of integration in the sport of people with disabilities. J. Hum. Sport Exerc., 9(Proc1), pp.S369-S375. Adapted physical activity, from an education perspective is entered process of integration especially in the education of people with special needs of all ages. The aim of this work is to analyze the issue of the integration of children and young people with disabilities in sport competition environment with a focus on public perceptions. Educational goal for children with disabilities is helping a harmonious development of their personality, how is it possible under the circumstances and this education of disabled is therefore targeted on effect on the child and the application of educational principles, rules and methods to the ability of a child with certain handicaps or disabilities can best develop. A child can live their life satisfaction and could become a full member of their society. In this study, the term integration in the educational context is understood as the union of attitudes, values, behaviors and future activities of various kinds. It affects both interpersonal and group relations and identities of individuals and groups. The need arises in contact with each other two different phenomena, situations, attitudes or activities. These may take the form of stress, conflict, problems affecting the balance and harmony of relationships, confidence and satisfaction of the life course. Integration is one of the tools that help overcome such contradictions. Paravaulting is a special rehabilitation method that focuses on gymnastics on horseback and is recommended for people with disabilities. This is a method that result can in most cases to a significant development of motor skills. Paravaulting like every sport has its specific classification, in which athletes are classified according to their degree of disability into categories. They are assigned a status so as to provide them with comparable starting point for training and competition and thus ensure "fair play". To ensure proper classification this allows athletes to compete on a level comparable despite the diversity of disability. In addition to the competitors with the medical classification is also involved in sporting activities beginning athletes and athletes without handicap. Results: We found that proper classification is important factor of ensuring the objectivity in the competition. Paravaulting gives the opportunity for children with disabilities, who are just starting with sports or play sports recreationally, to meet the great contest with their sports designs and in the process of integration compete in the category "dance and barrel", including special sports program for joint activities children and youth with handicap or without handicap. Key words: ADAPTED PHYSICAL ACTIVITY, INTEGRATION, SPORT, PARAVAULTING, HORSE, HANDICAP.
\end{abstract}

Corresponding author. Department of Adapted Physical Activity, Faculty of Physical Culture, UP Olomouc, Czech Republic. E-mail: jana.sklenarikova@upol.cz

8th INSHS International Christmas Sport Scientific Conference, 5-7 December 2013. International Network of Sport and Health Science. Szombathely, Hungary.

JOURNAL OF HUMAN SPORT \& EXERCISE ISSN 1988-5202

(c) Faculty of Education. University of Alicante

doi:10.14198/jhse.2014.9.Proc1.22 


\section{INTRODUCTION}

Adapted Physical Activity (APA) relate to physical activity and sport, in which special emphasis is given to the interests and abilities of individuals with limited conditions, disability, illness or age. These are services for individuals with unique needs for which it is necessary to apply leisure time activities, sports and wellness. These activities relate to lifelong activities of persons whose uniqueness of function, structure or appearance requires a professional approach in evaluating and adapting physical activities (Goodwin, 2000).

The aim of the APA is to support their socialization while respecting pro-integration societal trends. We can also speak about APA as about a set of physical activities (integrated, parallel or segregated) with the participation of people with special needs. A number of definitions of APA emphasize the multidisciplinary nature (eg. Sherrill, 2004), the interconnectedness of academic standards of practice (EUFAPA, 2006). Van Coppennolle (2004) and Doll - Tepper, DePaw (1996), almost identically characterized APA as movement, physical activity and sport with a special focus on the interests and abilities of persons with certain restrictions.

Ješina et al. (2011) reported that APA is implemented in the context of: a) Physical education (PE) Adapted physical education (APE) in schools or in special classes for pupils with special educational needs, APE in mainstream schools in an integrated environment - also referred to as integrated physical education (IPE); health physical education in mainstream schools and schools for pupils with special education needs; rehabilitation physical education in special schools. b) Sport - within sport organizations for persons with mental disabilities (Special Olympics); within sports organizations for persons with disabilities (IWAS); within sport organizations persons with visual disabilities (IBSA) in the context of sports organizations persons with hearing disabilities (CISS), in specific sports for persons with disabilities (eg, wheelchair basketball at IWBF, volleyball persons with disabilities WOVD); within selected Paralympic sports (such as sledge hockey, athletics, swimming), in an integrated approach with the unions of intact athletes (such as cycling or rowing). c) Recreation - in terms of physical recreation by Hodaň (2005). d) Rehabilitation - in terms of comprehensive rehabilitation according to Kábele (1988).

Ješina et al. (2011) divide the APA in terms of kinanthropology on sport, TV and gymnastic physical recreation. With an emphasis on the psychosocial dimension of physical activities carried out that can be part of a comprehensive rehabilitation. Although we are aware of the wide interest of APA (except those listed below including the issues of persons with autism spectrum disorders, behavioral disorders and attention, of seniors etc.), in this work we are dealing primarily with persons falling into categories: people with intellectual disabilities (ID); persons with health disabilities (HD), people with hearing impairments (HI), people with visual disabilities (VD), persons with long-term illness, people who are socially disadvantaged.

Paravaulting is a special rehabilitation method which ranks among the sports for disabled and is focused on gymnastics on horseback. Paravaulting is designed for individuals with particular types of disabilities. It is a method that can result in a significant development of physical skills in most cases. As part of the integration process athletes with health disabilities and without disabilities can practice and compete together (Zelinka, 2010). The primary objective is to achieve a specified therapeutic targets. Improvement of physical condition or help to maintain the current condition. Using horses as a facilitator and to encourage for athletes positive changes in behavior, remove or alleviate the symptoms of mental disorders or sensory deficits, develop social skills, psychomotor skills and concentration (Faksová, 2005) Sports club that decides to accept a child with a disability should work with the parents or legal guardians of the child 
under all circumstances and provide the conditions under the general specifics of the sport persons with disabilities.

In the pedagogical line in paravaulting enters the concept of integration especially in the field of behaviour and education for people with special educational needs of different ages (Ješina et al., 2011). The term integration is understood in the context of teaching as a union of attitudes, values, behaviors and direction of activities of the same kind. It affects both interpersonal and group relations and identity of individuals and groups. Her need arises in the contact of two dissimilar phenomenons, situations, attitudes or activities. These may take the form of stress, conflict, problems affecting the balance and harmony of relationships, confidence and satisfaction of the life course. Integration is one of the means that help to overcome such contradictions.

Sports and rehabilitation for disabled individuals incorporate newly established and innovative methods such as hippo therapy or paravaulting. Paravaulting like any sport for persons with disabilities has a specific classification in which athletes are classified into categories according to the degree of their disability. They are assigned a status to provide them with comparable starting point for training and competition and thus ensure "fair play".

What is classification?

Classification is a process in which a single group of entities (or units) are ordered into a number of smaller groups (or classes) based on observable properties that they have in common. Taxonomy is the science of how to classify its principles procedures and rules. It is applied in most scientific fields to develop systems of naming and ordering that facilitate communication, understanding and identification of inter-relationships (Tweedy \& Vanlandewijck, 2009).

Kebza (2005) with regard to terminology and the latest World health organization (WHO) classification distinguishes the following concept of disability: Disease (a disease in an objective sense usually involves a definite diagnosis) Illness (illness rather in terms of the currently deteriorating health, momentary incapacitation) Sickness (disease in terms of the experience of the social context of disease as a state when feeling unwell), disorder, injury (accidents, injuries), disability (handicap, disability, which may occur as the potential impact of the social consequences of the disease), health disability (physical or mental incapacity, which may occur as a possible consequence of objectively or subjectively conceived disease disease, illness) Impairment (any damage or loss in the context of psychological, physiological or anatomical structure or function that may occur as a result of possible disease).

WHO (1997) replaced the old model of impairment, disability, handicap with new model: impairment, activity, participation (Bartoňová, 2005), we still use (and probably some time we will use) the term person with disabilities. With the term disabilities we have in mind certain specific physical, sensory or mental damage of various kinds, the type and degree with the fact that this damage does not necessarily lead to a reduction of his abilities and skills in different environments (Ješina et al., 2011).

WHO (2011) released a groundbreaking document (International Classification of Functioning, Disability and Health, Figure 1) and is the official abbreviation ICF 2001. The aim of the ICF 2001 is to provide a uniform standard terminology and framework for the description of health conditions. Defines the components of health and some of the components of a healthy lifestyle (Ješina, et al., 2011). In November 2007 the General Assembly approved the ICF Classification Code. The code provides comprehensive 
guidelines, policies and procedures for the conduct of classification in sports governed by the IPC or its member federations.

From a sports science perspective, the code is significant because it explicitly mandates the development of evidence-based classification systems. This position stand has a twofold purpose:

- to provide a theoretically grounded description of the scientific principles underpinning classification in sport;

- to define the term evidence-based classification and provide guidelines for how it may be achieved.

Competition in paravaulting is based on systems of classification. The recently published ICF Classification Code mandates development of evidence-based systems of classification. Development of such systems is difficult because consensus regarding what constitutes evidence-based classification do not exist and because, to date, classification in Paravaulting sport has been largely theoretical.

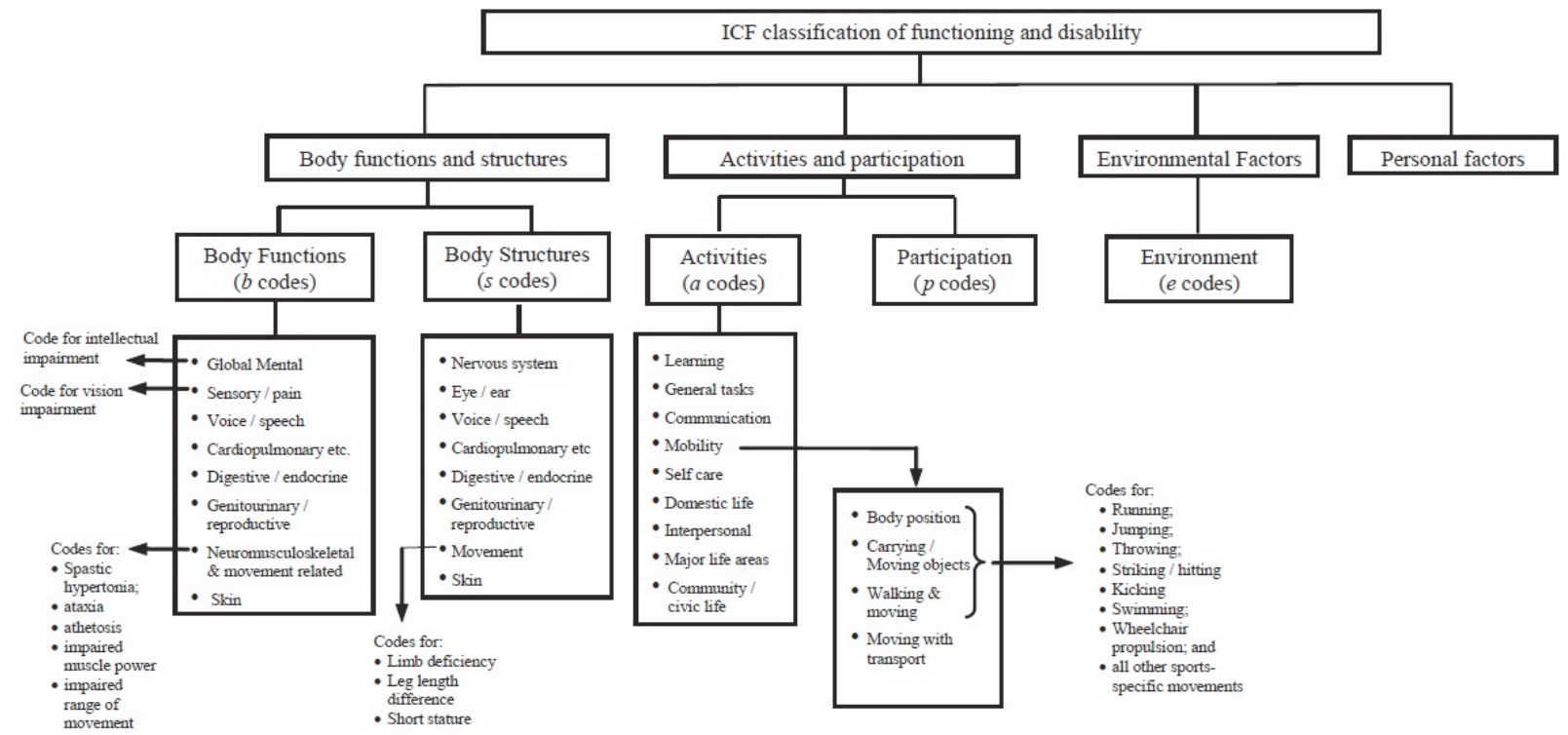

Figure 1. The structure of the International Classification of Functioning, Disability and Health (Tweedy \& Vanlandewijck, 2009)

The aim of this work is to analyze the issue of the classification of children and adolescents with health disabilities into an environment of paravaulting. The correct classification allows athletes to compete at a comparable level despite the diversity of disability. In addition to the competitors with so called medical classification are in sporting activities also involved starting athletes and athletes without disability.

\section{MATERIAL AND METHODS}

Division of athletes into categories according to the rules of paravaulting is carried out by a doctor or physiotherapist with the special course of Classificator. Paravaulting has its own categories as described in Paravaulting Rules (2010): 
LH(light handicap) - must fulfill a minimum level of disability. Locomotor system disorders occur in varying degrees. From the lightest, where the total momentum is not particularly limited up to the heaviest which prevents the momentum of the whole body or its parts (scoliosis, poor posture). Light brain dysfunction, light sensory and heart disease, neurosis and specific learning disabilities.

$\mathrm{MH}$ (mental handicap) - partial or deep, substantial deviations from the socially accepted and required standards for human behavior, degenerative processes of central nervous system (mental retardation, Down syndrome, behavior disorders).

$\mathrm{PH}$ (physical handicap) - particularly severe forms of cerebral palsy (especially quadruparetic), conditions after injuries or infections. For people with these disabilities it is difficult to obtain a realistic view of their situation and they tend to create high emotional dependence on the immediate family (cerebral palsy, peripheral paralysis, heavier sensory defects, multiple disabilities, etc.).

$\mathrm{HP}$ (healthy persons) - without handicap. They can compete in every competition besides Czech championship.

\section{DISCUSSION}

Process-focused research - what is required?

It has already been established that a necessary prerequisite for the development of evidence-based systems of classification is an unambiguous statement indicating that the aim of the system is to classify eligible impairments according to the extent of activity limitation they cause. This statement of purpose provides clear direction to researchers aiming to develop evidence-based systems of classification. The initial step requires development of objective, reliable methods for measuring both of the core constructs impairment and activity limitation.

Classification in sport

Competition is a defining feature of sport and one of several factors that differentiates sport from other physical activities such as exercise, activities of daily living or recreation. Moreover, competition is known to be a potent social factor that motivates many thousands of people to play sport. However, when competition is one-sided or predictable, motivation to participate in sport is reduced, particularly among the unsuccessful.

Classification in sport reduces the likelihood of one-sided competition and in this way promotes participation. Two main forms of classification are used in sport:

- $\quad$ performance classification

- $\quad$ selective classification

In paravaulting there are other important differences between performance classifications and selective classifications. First, there is generally no ceiling in selective classification systems - they are applied from grass-roots participation to the highest international level. Second, if a competitor in a selective classification system improves their performance through training; their class does not change, as it might in a performance classification system. In selective classification systems, effective training increases a person's competitive standing within their class. Finally, because selective classification systems only control for the effect of a small number of specified performance determinants, performance levels within a given class may vary widely. Consequently, although competition results can be used to evaluate the 
validity of methods used in a performance classification system, they provide only weak evidence in relation to selective classification systems.

In functional systems, the main factors that determine class are not diagnosis and medical evaluation, but how much the impairment of a person impacts upon sports performance. Classification combines medical information with information on the performance of athletes to assess the specific capabilities needed in paravaulting. Classification testing is done before the event, according to the statute of the competitor. It is a division of athletes into category that allow them to optimal success and the result will not be affected by disability, but by how an athlete trained or how talented he is.

\section{CONCLUSIONS}

The classification is designed to give all athletes a fair starting point for the competition. The system evaluates neurological function of athletes in relation to paravaulting in a way which will allow competing individuals with a similar degree of neurological impairment. The aim of the classification is to ensure that the distinguishing factor depended on training, skill level and competition experience than the neurological abilities. We found that the correct classification is an important factor to ensure the objectivity of the races. Paravaulting gives the opportunity for handicapped children, who are just getting started in sports, to meet with their idols during the competition.

This "fully inclusive" event is an achievement in paravaulting brings three different agencies together into one competition, providing a setting for disability and mainstream athletes to compete parallel with one another and at the same time socializing together in the same venue. Paravaulting for example allows the opportunity of expression, self - fulfillment and the development of creative skills. The paravaulting is performed by individuals with different disabilities, who learn with each other respect and tolerance. Athletes are practicing and competing together. In addition to the cooperation between them, exercising on the horseback leads to greater responsibilities, autonomy and physical coordination.

\section{ACKNOWLEDGMENTS}

This report was written as part of the project "Support for the creation of excellent teams and intersectoral mobility at Palacky University in Olomouc II." Reg.no. CZ.1.07/2.3.00/30.0041

\section{REFERENCES}

1. Bartoňová, M. (2005). Současné trendy v edukaci dětí a žáků se speciálními vzdělávacími potřebami v České republice. Brno: MSD.

2. Block, M. (2007). A teacher's guide to including students with disabilities in general physical education (3rd ed.). Maryland: Paul H. Brooks Publishing Co.

3. Doll-Tepper, G. \& Depaw, K.P. (1996). Theory and practice of adapted physical activity: Research perspectives. Sport Science Review. Adapted Physical Activity Quarterly, 5, pp.1-11.

4. Eufapa (2006). Bylaws of European Federation of Adapted Physical Activity (Stanovy o.s. Evropská federace aplikovaných pohybových aktivit.)

5. Faksová, M. (2004). Paravoltiž. Olomouc: Katedra Aplikované tělesné výchovy.

6. Hodaň, B. (2000). Tělesná kultura - sociokulturní fenomén: východiska a vztahy. Olomouc: Univerzita Palackého v Olomouci. 
7. Ješina, O., Hamřík, Z., et al. (2011). Podpora aplikovaných pohybových aktivit v kontextu volného času. Olomouc: UP v Olomouci.

8. Ješina, O., Kudláček, M., et al. (2011). Aplikovaná tělesná výchova. Olomouc: Univerzita Palackého v Olomouci.

9. Ježková, A., Jablonská, J. \& Blažek, D. (2010). Pravidla paravoltiže. Praha: Česká hiporehabilitační společnost

10. Kábele, F. (1988). Somatopedie. Praha: Univerzita Karlova.

11.Kebza, V. (2005). Psychosociální determinanty zdraví. Praha: Academia.

12. Sherrill, C. (2004). Adapted physical activity, recreation and sport: Crossdisciplinary and lifespan (6th ed.). Boston, MA: WCB/McGraw-Hill.

13. Tweedy, S.M., Van Landewijck, Y.C. (2011). International Paralympic Committee position stand: background and scientific principles of classification. In Paralympic sport. British Journal of Sports Medicine, 45(4), pp.259-69

14.Van Coppenolle, H. et al. (2004). CD -ROM "Adapt"- The common European curriculum foundations of adapted physical activities and sports persons with disabilities. THENAPA.

15.World Health Organization. (2007). Promoting Physical Activity and Active Living in Urban Environments. Geneva: Author.

16. World Health Organization (2011). International Classification of Functioning, Disability and Health. Geneva.

17.Zelinka, J. (2007). Absolventská práce. Paravoltiž a Hipoterapie. Praha: Palestra. 